\title{
SISTEMA EDUCATIVO DE LA POLICÍA DE INVESTIGACIONES DE CHILE
}

Jefatura de Educación Policial 


\section{RESUMEN}

Un notable avance ha experimentado el sistema educativo de la policía de investigaciones en los últimos diez años, lo que ha permitido mejorar considerablemente la calidad de la formación que entrega. Por esta razón, su actividad docente es ampliamente reconocida por su enfoque humanístico-científico, considerar el contexto cultural y promover el desarrollo social, artístico y deportivo de todos los miembros de la institución.

Este artículo expone, en primer término, luego de un breve recorrido por el marco legal, la filosofía de la policía de investigaciones, para a continuación describir, a grandes rasgos, la estructura de la formación educacional y los perfiles de los egresados.

\section{ABSTRACT}

During the last ten years, the Investigation Police Forces' educational system has experienced a great advance, which has considerably improved its quality. Therefore, its educational activity is widely recognized due to its humanistic-scientific approach; because it considers the cultural context and stimulates the social, artistic and sports activities of all de institution's members

In the first place, after a brief account of the legal frame, this paper unfolds the investigation police's philosophy, offers an outline of its educational structure and its graduates' profiles. 


\section{SISTEMA EDUCATIVO DE LA POLICÍA DE INVESTIGACIONES DE CHILE}

\section{INTRODUCCIÓN}

El sistema educativo de la Policía de Investigaciones de Chile se apoya sobre dos pilares: la modernización tecnológica -que ha permitido generar iniciativas académicas de gran impacto y eficiencia- y la formación ética y en derechos humanos.

La institución dispone para la formación, capacitación y perfeccionamiento profesional del personal, de la Escuela de Investigaciones Policiales, la Academia Superior de Estudios Policiales y el Centro de Capacitación Profesional, establecimientos educacionales que funcionan de manera independiente, pero bajo la supervisión de la Jefatura de Educación Policial. Su misión es orientar, supervisar, planificar, organizar y controlar las actividades docentes de todos los niveles, con el objeto de materializar las políticas educacionales de sus planteles.

Con la finalidad de dar debida importancia a la investigación policial, la superioridad institucional obtuvo del poder legislativo la promulgación de la Ley $\mathrm{N}^{\circ}$ 19.584, que modificó la Ley $\mathrm{N}^{\circ} 18.962$ Orgánica Constitucional de Enseñanza (LOCE), incorporando a la Escuela de Investigaciones Policiales y a la Academia Superior de Estudios Policiales como planteles de educación superior reconocidos por el Estado.

De esta manera, los establecimientos de educación superior de la Policía de Investigaciones de Chile están facultados para desarrollar actividades docentes, de investigación y extensión de nivel superior. 
Cabe señalar que la policía de investigaciones lleva a cabo un importante proceso de desarrollo, cuyos ejes se contienen en los planes estratégicos Fénix 1 y Fénix 2, que apuntan a modernizar la gestión y a mejorar la dotación de recursos humanos, tecnológicos y de infraestructura, con el propósito de colaborar eficientemente en la implementación de la Reforma Procesal Penal. En el Plan Fénix 2 se encuentra el análisis y revisión del sistema educacional de la policía civil en pro de un mejor desarrollo de la formación de su personal.

\section{FILOSOFÍA INSTITUCIONAL}

La misión de la Policía de Investigaciones de Chile es contribuir a satisfacer las necesidades de seguridad individual y social de las personas, entregando un servicio policial investigativo, eficiente y eficaz.

La policía civil es una entidad investigadora confiable, que desarrolla su actividad con estricta sujeción al estado de derecho y en un marco de conductas éticamente válidas.

Entre sus desafíos están la modernización y medición de la gestión policial, la implementación de alianzas estratégicas y el compromiso de servicio a la comunidad. Valora el trabajo en equipo, el empleo de tecnología, la capacitación permanente y el compromiso con sus objetivos. Asimismo, ofrece igualdad de oportunidades a sus integrantes y se constituye en una eficiente vía de superación profesional y personal.

\section{ESCUELA DE INVESTIGACIONES POLICIALES (ESCIPOL)}

La Escuela de Investigaciones Policiales tiene como propósito la formación profesional, científica y técnica de los futuros oficiales policiales. Este plantel busca formar detectives dotados de una amplia gama de valores sociales, individuales e institucionales, con una moderna preparación teórico-práctica (tanto científica como tecnológica), con principios claros y valores sólidos, y con buen criterio frente a decisiones relevantes que deban asumir. 
Los objetivos del programa de formación de detectives abarcan, entre otros, los siguientes aspectos: énfasis en lo investigativo, en ética, en conocimientos jurídicos, en liderazgo administrativo, en el dominio de las acciones que demanda la Reforma Procesal Penal y en técnicas de seguridad personal. Al igual que las otras escuelas matrices de nuestro país, el aspirante vive interno en el plantel, lo cual facilita la adquisición de la cultura institucional.

Asimismo, la formación integral de los aspirantes recae en el Departamento de Instrucción, formado por oficiales instructores, cada uno a cargo de un curso. La misión de este departamento es ayudar a los estudiantes a enfrentar desafíos y solucionar problemas de modo progresivo y autónomo.

Los alumnos ingresan a este plantel en calidad de aspirantes, y egresan como investigadores policiales luego de aprobar los tres primeros años del plan de estudios. El cuarto año corresponde a la práctica profesional en las brigadas criminales, bajo el control de un oficial tutor. Finalmente, el quinto año está destinado a la especialización, en jornada vespertina.

El título de investigador policial comprende las siguientes menciones: Homicidios, Extranjería y Policía Internacional, Narcotráfico, Robos, Delitos Económicos, Inteligencia Policial, Delitos Sexuales, Delitos Informáticos, Huellografía y Dactiloscopia, Crimen Organizado, Balística, Delitos Ecológicos e Investigaciones Internas. Las especialidades se imparten según la evaluación de las necesidades institucionales.

El perfil del estudiante que ingresa a la escuela ha evolucionado positivamente, lo que se explica por las siguientes razones: una exigente selección; la edad promedio de los postulantes ha aumentado, lo que implica mayor madurez en la decisión de ser policía; la edad máxima para postular es de 27 años; frecuentemente, los postulantes han estudiado una carrera (o parte de ésta), ello redunda en un mayor conocimiento y experiencia en áreas específicas, además de más disciplina para enfrentar la actividad académica; ha aumentado el número de mujeres, cumpliéndose de esta manera la política institucional de no-discriminación e igualdad de oportunidades. 


\section{ACADEMIA SUPERIOR DE ESTUDIOS POLICIALES (ASEPOL)}

La ASEPOL es el plantel de estudios superiores destinado a la preparación de los futuros jefes de la institución y al perfeccionamiento de los oficiales. Por lo tanto, su formación está destinada exclusivamente a un sector limitado del personal: el más selecto, de mejores calificaciones y, que cumpla con los requisitos de ascenso. Dicta el curso de Alto Mando y, además, confiere el título de Oficial Policial Graduado, con el grado académico de Licenciado en Ciencias de la Investigación Criminalística.

El objetivo general del Curso de Alto Mando es establecer un espacio de diálogo reflexivo entre académicos, personalidades del ámbito nacional y oficiales alumnos, con el fin de consolidar la seguridad ciudadana de nuestro país. Su plan de estudios considera siete áreas temáticas: desarrollo económico; ética y liderazgo; información, comunicaciones y cultura; reforma del Estado; derecho y desarrollo jurídico; seguridad ciudadana; gestión directiva y planificación estratégica.

Por su parte, el programa de Oficial Graduado en Investigación Criminalística convoca a policías por estricto orden de escalafón.

Considera, como áreas transversales, a las ciencias jurídicas, criminológicas y humanas. Además, cuenta con cursos complementarios consistentes en seminarios (derecho internacional, derecho humanitario, políticas de desarrollo, historia policial, seminario de tesis, entre otros) y con otros cursos específicos (educación física, informática, protocolo, y otros). El perfil de egreso está dado, prioritariamente, por la carrera funcionaria a la que están vinculados los oficiales alumnos.

La academia superior ofrece, además, diplomados en Criminología, Alta Dirección Pública y Gobierno Electrónico, Inteligencia y Prospectiva Estratégica. También actualizaciones pedagógicas, cursos para la Reforma Procesal Penal, y Manejo de Conflictos y Crisis. Estos diplomados se realizan en conjunto con diversas universidades nacionales y extranjeras. 


\section{CENTRO DE CAPACITACIÓN PROFESIONAL (CECAPRO)}

El Centro de Capacitación Profesional (CECAPRO) es un plantel de educación de nivel técnico que depende de la Jefatura de Educación Policial y cuyos principales fines son formar, capacitar y perfeccionar al personal de las Plantas de Apoyo General, de Apoyo CientíficoTécnico (profesionales y técnicos) y de Oficiales.

El Centro de Capacitación Profesional está facultado para planificar e impartir todos aquellos cursos que sean de su competencia. Se encuentra autorizado para establecer convenios y coordinar acciones con otros organismos de carácter académico, sean estos nacionales o extranjeros. El CECAPRO es también la entidad encargada de impartir cursos de especialización para oficiales policiales. 